\title{
The Top Ten Developments in Studies on Chinese Humanities in 2017
}

\author{
Translated by Caterina Weber
}

Over the past years, research in the humanities has become increasingly rich and varied in China; it is also undergoing significant changes. In order to provide a timely summary of new breakthroughs and issues in the humanities, to promote the advancement and variety of the research in this area, and to enhance the degree of awareness and interest of the public for this field, the Journal of Literature, History, and Philosophy (文史哲) and China Reading Weekly (中華讀書報) jointly launched an annual “Overview of the Top Ten Developments in Chinese Humanities." This is the fourth consecutive year we have collaborated on this publication.

The following ten issues in the Chinese humanities have been selected for 2017 .

\section{Following Changes in the Cultural Environment, Scholarly Circles Have Consciously Tried to Create a Characteristically Chinese-Style Academic Discourse}

Because of the situation known as "Western learning spreading eastward," Chinese scholarship has long suffered from aphasia. Given the increasingly exposed internal ambiguities that inspire modernity, the subjective consciousness of non-Western countries in particular in the process of modernization has gradually intensified. The course of human history has shown major improvements, and the progress of globalization, symbolized by Westernization, has progressively yielded to the pursuit of indigenization in the area of cultural ideology in many countries and regions.

This process is particularly noticeable in contemporary China. Localization has become a clear trend, as Chinese academia faces historic change from the rise of the great powers. Precisely because of this major shift in the cultural mood, in 2017 an increasing number of newspapers and magazines, as well as more and more academic fields and scholars, began to focus on the Chinese 
model, exploring the establishment of a system of philosophy and social sciences with uniquely Chinese characteristics. Some scholars have declared that the overall target of Chinese humanities and social sciences is that of shaping a Chinese discourse-building a national discourse that matches the imposing background of the rise of the great powers. Various signs indicate that academic circles are fully aware that launching a Chinese-focused academic discourse has become their new task.

\section{As Research on the Silk Road Progresses, the Notions of "National Identity" and "World Order" Have Attracted General Interest}

In May 2017, the first Belt and Road Forum for International Cooperation opened and marked a new phase in recreating the Silk Road. This shows that the "turn toward the outside" of a China that had been introverted for several centuries is picking up speed. This historical turn brings with it related advancement in academic research. A renewed interest in the notions of country, ethnic groups, and regions in traditional China, reflections on the meanings of "China," of "Cathay," and subsequently the refining of a new model that exceeds that of a world order based on a nation-state, extracted from thousands of years of a society's achievements, has gradually become a central discussion point among Chinese historians.

Many of the recent scholarly achievements, such as "China from the Perspective of Its Neighbors," a clarification of "Inside and Outside Historical China," "A Perspective of China from Beyond Its People," the "Inner-Asian Personality" that emphasizes ancient dynasties, and so forth, all point to the traditional notions of "national identity" and "world order" that were temporarily put aside under the influence of contemporary factors. At a time when nationalism is spreading and regional conflicts are intensifying, some scholars believe that a better world order can be achieved through a "world system" based on the idea of minimizing mutual harm, instead of a "nation-state model" based on seeking one's own interests.

Academics are Calling for the Reestablishment of Chinese Politics and Philosophy and for an Urgent and Comprehensive Reevaluation of Classical Values

Mainstream twentieth-century writing on politics and philosophy most often takes liberal values as a theoretical prerequisite, but in recent years the Chinese 
pattern of social governance has become more prominent; and yet, under the guidance of Western liberal leaders, political practice continuously faces difficult situations, which causes this pattern to be called in question. In fact, a richer political ideology is needed, in which Confucian thought, politics, and philosophy become part of people's perspective and academic circles call for a "reestablishment of Chinese politics and philosophy" "starting from the very sources of Chinese civilization."

Because Confucian teachings and liberalism both have a system based on the disposition of human nature, the theory of human nature has consequently become the starting point for a rethinking of politics and philosophy and a fresh restructuring thereof. Some scholars point out that liberalism considers some specific people rational without making distinctions: this deviates from reality, and the equality it advocates remains at abstract. Confucian theories on human nature distinguish between sages, sovereigns, and ordinary people, and they value the differences between people and emphasize their ability to adjust. Establishing a model of political system strata based on the latter is more applicable to reality. The precise disposition of human nature in the system and arrangements of human society as represented by ancient Chinese Confucian teachings is being given an overall reevaluation.

\section{4 \\ The Usual Paths for the Social Sciences are Narrowing, and "Historical Imperialism" is Gradually Gaining Ground}

Over the past few years, the legitimacy of liberalism commonly regarded as ingrained in the social sciences has been heavily challenged. Based on this, some scholars believe that an era of rapid development in the social sciences is coming to an end. Because they were constrained by theoretical paradigms, many scholars turned to studying this area from a historical perspective. For example, researchers in politics began studying the history of political systems or researching the history of political thought; legal research took to studying the history of China's legal system and the history of legal thought on an unprecedented scale; economists began paying close attention to the history of economic thought and to the history of economics, and so on. This shift caused a fresh upsurge of "historical imperialism," seen repeatedly in Chinese social sciences.

The "historical imperialism" that is gradually gaining ground refers to various academic subjects, such as sociology, increasingly often choosing a historical angle as their direction of research or carrying out meticulous research on the history of their own discipline or on the history of learning. To some extent, 
research in the social sciences uses the working methods of historiography but all the currently emerging major "historiographical directions of study" have made methodological choices because of control over research directions. This indicates that at present the social sciences in China are generally in a phase of hesitation and disorientation.

\section{The Phenomenon of "False" Ancient Texts Is Becoming Increasingly Worse: Radical Reform Has Become a Matter of Top Priority}

Over the past several years, with the increasing digitization of ancient texts and the popularity of databases of classics, we have seen a marked rise in the collection and publishing of classical texts. This is of great significance for the promotion of academic development while carrying on traditional culture. However, following the expansion of this market, some of the institutions in charge of the collection and publication were keen on quick success and immediate benefit and utilized the advantages brought by digitization: they started to blindly produce large quantities of low-quality, duplicated materials, to the point of disregarding academic standards and working in a rough and sloppy way, using other people's achievements without acknowledging sources, and proliferating publications riddled with "false findings" and "false annotations." This ever-worsening phenomenon of "false arranging" of ancient texts has destroyed the academic balance in this area and has made it difficult for many a puzzled reader to determine the quality of a text.

In 2017 , scholars thoroughly reformed the way that ancient scriptures are collected, and calls for distinguishing the real from the false became even stronger. Some scholars pleaded for those sorting and publishing ancient books to put more energy and effort into original creation, to produce more annotations that readers "cannot look up" and yet "will find useful." Reinforcing academic self-discipline and publishing management, as well as raising the access threshold and improving evaluation standards, have at present become vital tasks in the publishing of collections of ancient books.

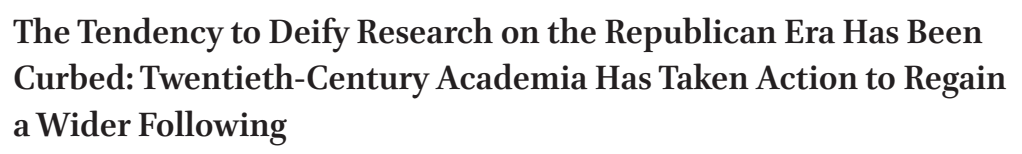
Curbed:Twentieth-Century Academia Has Taken Action to Regain a Wider Following

Since the 1990s, a certain view on matters such as the families of scholars and the foundations of Chinese civilization has become rather influential in 
academic circles, namely that it is very difficult for later generations to be associated with scholars from the Republican era. Promoted and magnified by the media, by the public, and by intellectual circles, this image was enlarged to the point of an excessive beautification or even deification of eminent scholars and academic achievements from the Republican era. Ever since the shift to a new century, this trend has been quite widely criticized, and in 2017 such challenges became particularly fierce and intensive. Many academics point out that scholarly research from the Republican era combines the Chinese and the Western, links the ancient and the modern, and has firmly established the basis of scholarship in contemporary China, but that in its initial stages it inevitably also had its immature, imperfect aspects, and that there is a considerable difference between its standards and the reality today.

Discrepancies in the evaluation of Republican scholarly materials are rooted in the differences between the methods for creating contemporary Chinese scholarship: the key is whether the data, or the use of a specific theoretical tool from a sociological point of view, are seen as the right path for the development of contemporary scholarship. A more relevant question is whether this long-lasting "Republican academic fever" is, in fact, a "Republican culture fever" or simply a "Republican fever" —and whether the excessive favoring of the status of Republican scholarship ultimately reflects a kind of stance toward the history of society itself. T. Ames's Confucian Role Ethics: A Vocabulary Has Been Published

Unrestrained individual freedom is the foundation of, and the primary essence of, contemporary Western political correctness. In recent years, however, an increasing number of scholars worldwide has been attributing the existential crisis humanity is facing in the twenty-first century to the near-extremist tendency to see individualism as a "primary teaching." Therefore, some academics such as the American scholar Roger T. Ames are calling on "Confucian role ethics" as an ideological resource to advance a "second enlightenment" in the present world.

The Chinese translation of Ames's book Confucian Role Ethics: A Vocabulary was published in 2017. By exploring a fundamental concept emphasized in traditional Confucian teachings, that of "roles in society given to people through specific interpersonal relationships," the book attempts to develop a kind of "moral view of life based on the direct experience of entirety" and thereby challenges Western individualism. Ames's supporters find that this book 
provides a significant ideological resource for solving global struggles with moral principles. His critics worry that putting excessive emphasis on specific roles will cover up Confucian universality and perpetuity. What part Confucian Role Ethics will play in reestablishing a world cultural order, and whether it can provide sufficient scholarly support for the "second enlightenment," is a question of time and experience.

\section{The Formation of a Genealogy of Knowledge on Women's Writing Is Making Steady Progress: Gender Analysis Has Become the Foundation of Research in This Area}

In the 1980s, Chinese women's writing became an important element in the trends of literary thought. Female experiences, appeal, and writing then developed into a major literary phenomenon at the turn of the twenty-first century. These texts had a more exquisite, sensitive way of depicting and pondering the specific physical, sexual identity, and life position of women; they tried to understand and contemplate by making an appearance in the history of human society, to some degree breaking the dominant position of the culture of paternal authority and its absolute freedom of expression, changing the object-like position of women being scrutinized, consumed, even artificialized.

Since the twentieth century, "gender" has been widely used as one of the possible categories for literary analysis. The scope of research on women's literature became wider, and the underlying connections between women's literature and social history developed into an important research area. In 2017, the creation of a genealogy for knowledge on women's literature has advanced steadily, and gender analysis came a step closer to becoming the main method of analysis for literature with a gender-specific undertone. Gender analysis from a female viewpoint caused scholarly, cultural, and social phenomena previously obfuscated by an all-male standpoint to reemerge and be reinterpreted, revealing a considerably different discourse.

Silverware Retrieved from a Riverbed Allowed Archaeologists to
Prove the Existence of Zhang Xianzhong (張獻忠, 16o6-1647), in a
Moment of Triumph For Public Archaeology

Between January 5 and April 12, 2017, the excavations at an archaeological underwater dig to retrieve sunken silverware in the Pengshan District of Sichuan celebrated a first major success: over thirty thousand relics from the mid- to 
late Ming era were retrieved, the majority of which were large quantities of silver ingots and silverware obtained by Zhang Xianzhong, a local Ming official. This inland underwater archaeology breakthrough has not only allowed us to confirm the myth of Zhang sinking silverware in the river but also, more importantly, has revealed concrete details on aspects of mid- to late Ming society, political affairs, and military affairs and has been proclaimed one of the most important archaeological finds from the Ming-Qing era since the excavations at the Dingling Ming tomb.

This archaeological find has further stimulated public participation in archaeology and has pushed public archaeology to a new stage. Somewhat distinct from the relatively obscure practices of traditional archaeology, public archaeology is undertaken with the full support of local authorities, enhances the public profile of the site, and functions as an attraction for local cultural and tourism projects. From the very start, these excavations of "silverware in the river" were intentionally open to the public and, in parallel with the excavation work, the organizers held a "Symposium for Historians at the Site of Silverware Sunk in the River at Pengshan" and made preparations for the excavation site to be made into a tourist attraction. Together with the Marquis of Haihun Tomb in Nanchang, whose excavation also continues to make progress, this find marks the swift development in public archaeology in recent years.

\section{Artificial Intelligence Technology Advances by Leaps and Bounds: The Wisdom and Moral Principles of Human Civilization Are Facing a Severe Challenge}

Because of its use of "reinforcement learning" algorithms and its being unrestricted by human knowledge, the program AlphaGo Zero cuts a splendid figure; because of this, it is said that 2017 could be called the "first year of artificial intelligence [AI]." This indicates that the science and technology behind AI has had remarkable developments, which brings an unprecedented challenge to human wisdom and moral principles: there is a danger that the human species will be forced to give way. There are even those who raise an alarm that "A post-human era is approaching!"

Over several thousand years, the foundations of human civilization and morality, wisdom, freedom, intuition, and benevolence jointly stood for the intrinsic nature of humankind and were enjoyed by humans alone. Now, however, with this cognitive basis already established, the "intelligence" and creativity of human civilization has already started being handed over to machine-based developments. In the future, intelligent machines will increasingly be their 
own masters in carrying out policies and acts involving ethical principles; if their inspection and control of these actions are not implemented effectively, causing them to conform to norms of impartiality and morality, not only will it become impossible for AI to bring about the intended benefits to humankind but the safe existence of humankind and its dominant role in policy-making will also be threatened. How the essence of humankind will be redefined after machines grow into self-controlled "manmade moral beings" that not only have wisdom but also possess ethical qualities has clearly become an extremely urgent contemporary research topic in the humanities. 